\title{
Management of Oviductal Prolapse in Duck
}

\author{
Dimpi Choudhury ${ }^{1 *}$, Joga Dev Mahanta ${ }^{1}$ and Karabi Phukan ${ }^{2}$ \\ ${ }^{1}$ Department of Poultry Science, College of Veterinary Science, \\ Assam Agricultural University, Guwahati, Assam, India \\ ${ }^{2}$ Department of Veterinary Pathology, College of Veterinary Science, \\ Assam Agricultural University, Guwahati, Assam, India \\ *Corresponding author
}

\section{A B S T R A C T}

\section{Keywords}

Duck, Oviduct,

Prolapse, Treatment

Article Info

Accepted:

26 March 2020

Available Online:

10 April 2020
Eight months old Vanaraja Hen was brought with the swelling and prolapsed of the oviduct. On examination, the oviduct was protruded from the vent with no retention of egg. The bird is restrained carefully and then the protruded part of the oviduct is washed with Normal Saline Solution. The protruded parts are rubbed with Lignocaine gel and carefully the oviduct was retracted inside and then purse string suture is applied. This case describes the successful treatment and management of the condition by treating the affected part. Antibiotic course along with other supportive treatment such as anti-inflammatory and vitamins was given to the bird.

\section{Introduction}

Prolapse (pickout) is the condition where the turning inside out of the oviduct and rectal organs through the vent, to the extent of not retracting back. It is commonly seen mainly in young female birds at the initial stage of laying period (Singh et al., 2017). An egg may or may not still be contained within the prolapsed structure. These kinds of cases may lead to necrosis of the areas if left untreated (Peter, 2002). Prolapse usually occurs as a consequence of tenesmus, weakness of perirectal and perianal connective tissues or muscles, uncoordinated peristaltic contractions and inflammation or edema of rectal mucous membranes, stress which predispose to prolapse (Naik and Jyothi, 2013).

Other causes include structural or mechanical interference, abnormally shaped or softshelled eggs, infection, nutritional deficiencies, inadequate dietary supplementation for hens during breeding, repeated breeding cycles and other poor husbandry practices (Peter, 2002). It may also occur secondary to any condition that causes chronic, excessive straining such as normal physiologic hyperplasia during egg laying. 


\section{Materials and Methods}

An 8 months old female Vanaraja Hen of approximately $1.8 \mathrm{Kg}$ body weight was presented with protruded mass from the vent. The protruded part was severely swollen with no retention of egg and it was diagnosed as Prolapse of oviduct. The hen was not taking any feed and recumbent (Fig. 1).

\section{Treatment}

The bird was restrained carefully and the protruded parts are thoroughly washed and
Lignocaine $2 \%$ gel is applied to induce local anaesthetic affect in the region. Carefully the protruded part was reduced inside the body and a purse string suture placed around the vent.

Betadine solution along with Himax ointment was advised to apply topically for the next 10 days to protect the wound from flies and helps in healing. A dose of Enrofloxacin, Meloxicam and B complex Vitamin was injected for the next 5 days to suppress the infection and improve the overall health of the bird.

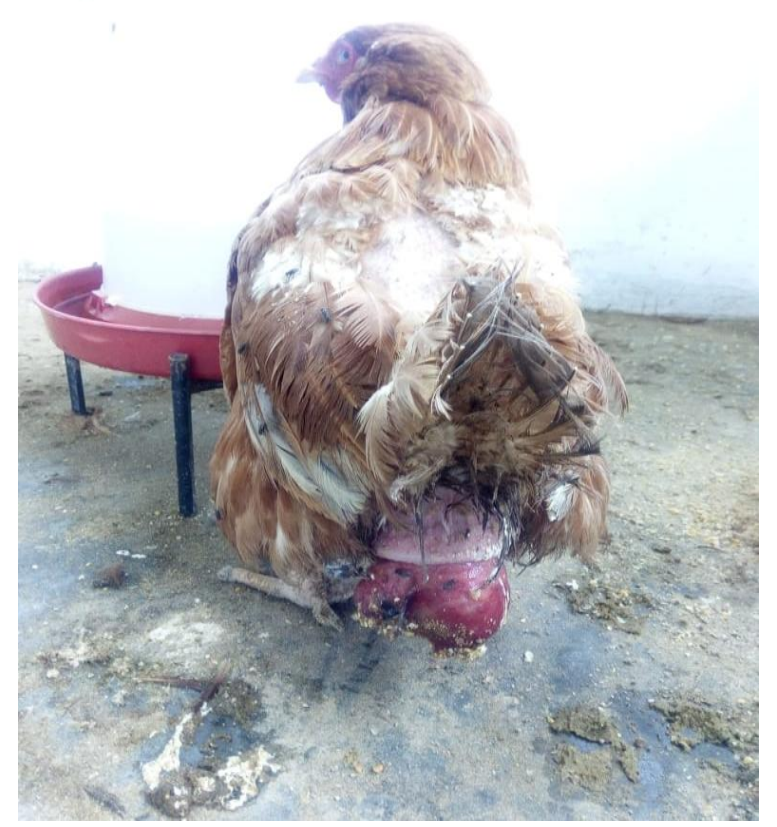

Fig.1 Prolapse of oviduct of a Vanaraja hen

Young birds laying extra-large eggs were prone to egg bound Crespo et al., (2003) and prolapse. Unusual large or oddly shaped egg, infection of the oviduct, premature early laying etc. are some of the causes of prolapsed in birds. Some researchers (Joyner, 1994 and Harrison, 1986) also reported those prolapses are caused by oviductal muscle malfunction is due to lack of Calcium, Selenium, Vitamin E and other nutritional deficiencies and stress. The prognosis is guarded as the tissues do have a tendency to prolapse again. Obese and under exercised birds were more prone.

\section{References}

B. Joy and T. R. Divya (2014). Egg bound and vent prolapse in chicken - a review of two cases Bangl. J. Vet. Med. 12 (1): 91-92.

Crespo R and Shivprasad HL (2003). Developmental, metabolic and other noninfectious disorders. In: Saif YM, 
ed. Diseases of poultry (11th edn), Iowa state press, Blackwell publishers. 1231.

Joyner K.L.(1994). Theriogenology. In: Ritchie BW, Harrison GJ, Harrison LR. Avian Medicine, Principles and application. Lake worth $\mathrm{Fl}$ : Wingers publishing. Pp. 758-773.

Laishram Kipjen Singh, W. Pipelu, G.K. Mishra, Nitish Kharayat, M.K. Patra, S.K. Singh and

Kumar, H. (2017). Management of Egg Bound and Oviductal Prolapse in Duck. Int.J.Curr.Microbiol.App.Sci. $\quad$ 6(11):
3972-3974

Peter S. Sakas (2002). Complications of Egg Laying Behavior. Essentials of Avian Medicine: A Guide for Practitioners, Second Edition. Published by the American Animal Hospital Association Press.

Srinivas Naik and Jyothi Sree Ch. (2013). Surgical management of complete colorectal prolapse in a grower emu chick (Drommaius novaehollandiae). Int. J. Agric. Sc \& Vet. Med. 1(2):23203730

\section{How to cite this article:}

Dimpi Choudhury, Joga Dev Mahanta and Karabi Phukan. 2020. Management of Oviductal Prolapse in Duck. Int.J.Curr.Microbiol.App.Sci. 9(04): 3033-3035.

doi: https://doi.org/10.20546/ijcmas.2020.904.354 